\title{
Reflections and Discussions on the Socialization Service of University Libraries
}

\author{
Fei Wang*, Xu Yu \\ Jiangxi Police Institute, Jiangxi, Nanchang, 330038 Yuzhang Normal University, Jiangxi, Nanchang, 330038 \\ *739960103@qq.com
}

\begin{abstract}
The establishment of university library is not only for our students, but also for the general public, now the university library has become the offensive of many colleges and universities. The convergence of all kinds of literature in the library can bring educational function to the public. The socialization of university libraries can improve the cultural and moral cultivation of the masses and promote the harmonious development of society. The development of university library cannot be separated from the ordinary people, at the same time, the public also has expectations of university library. However, there are still many problems to be solved in the process of socialization of university libraries, and this paper analyzes the current situation of socialization service of university libraries, explores the problems of socialization of university libraries, and puts forward corresponding suggestions for improvement, hoping that university libraries can serve the society and the public.
\end{abstract}

Keywords: Colleges and universities, Library, Socialization, serve

\section{对高校图书馆社会化服务的思考与讨论}

\author{
王飞* 喻旭
}

江西警察学院 江西 南昌 330038; 豫章师范学院 江西 南昌 330038

*739960103@qq. com

\section{摘要}

高校图书馆的设立不仅仅是为了本校学生，还是为了社会大众，现今高校图书馆对外界开放已经成了众多高校 的攻势。图书馆中各类文献资料的汇聚，能够给社会大众带去教育功能。高校图书馆社会化能够提高人民大众 的文化道德修养，促进社会和谐发展。高校图书馆发展离不开普通民众，同时社会公众对高校图书馆也怀有着 期待。但现今高校图书馆社会化过程中仍然存在着许多问题需要解决, 本文从高校图书馆社会化服务内涵出发, 分析高校图书馆社会化服务现状，探寻当今高校图书馆社会化存在的问题，并提出相应的改善建议，期望高校 图书馆能够服务社会、服务大众。

关键词: 高校; 图书馆; 社会化; 服务

\section{1. 高校图书馆社会化服务内涵}

随着我国社会的不断进步与发展, 人们的生活水 平也越来越高, 人民也需要更多的文化产品来丰富自 己的精神生活, 于是社会大众越来越重视平等的文化 享有权, 希望图书馆资源能够面向社会大众进行开放。 图书馆是人类知识的宝库, 其存在着保存人类文化遗 产、开发信息资源、参与社会教育的职能的功能。图 书馆作为公共文化机构, 是需要为大众开放, 给大众
提供学习和查阅资料的渠道的。公共图书馆社会化服 务能够促使广大人民群众接受社会文化教育, 提高社 会大众的素养。高校图书馆则是设立在高校之内的文 献聚集地, 主要为学校教学和科学研究服务。将高校 图书馆面向大众推出社会化服务这一概念首先是由 美国提出的, 在 20 世纪 80 年代时引起了我国的注意。 高校图书馆社会化服务就是将高校中的图书馆开放 向大众, 使其功能不再只面对学生及教师群体, 以达 到更大的社会效益。这个概念的提出正符合中国的国 情, 将有限的资源提供给尽可能多的人使用, 满足人 
们的文化需求。

\section{2. 高校图书馆社会化服务现状}

党的十八大提出要开展全民阅读活动, 促使阅读 成为每个公民的良好习惯, 但中国的平均阅读水平与 国际社会, 甚至是发达国家相比并不高, 而我国的有 关阅读的基础设施和服务水平并不高, 这些因素都在 严重制约着我国的平均阅读水平的提升。

现在的高校内都设有或大或小的图书馆, 其中存 放的文献资料也有许多。但经过研究调查发现, 现在 高校内的文献资源优势并没有很好地发挥出来, 高校 图书馆内的文献利用率只有 $30 \%$, 大多数学生在借阅 图书时大多偏向热门书籍或是专业学习需要的书籍。 并且许多高校图书馆处于封闭的状态, 只针对校内的 教职工或学生开放, 并没有做到向社会大众服务这一 目标, 这也就导致高校图书馆内的大部分文献资源处 于闲置的状态。国内对高校图书馆社会化服务的研究 利用起步较晚, 致使许多高校对图书馆社会化服务意 识的认识并不强, 社会大众和学生群体在日常中理所 应当地将高校图书馆作为高校内独有的资源。在一些 对公众开放的高校图书馆中, 社会化服务功能比较单 一, 只能在图书馆中进行简单的查阅资料, 没有其他 的个性化服务满足大众需求, 并且对进入图书馆的人 数和时间都有严格限制, 这大大削弱了高校图书馆社 会化服务能力。在外国许多高校内, 图书馆是作为社 会公众资源存在的, 高校校园也是向大众开放的, 任 何人都能进入图书馆查阅文献、借阅书籍、打印资料, 将高校图书馆与大众图书馆之间的界限打破, 这也在 一定程度上提升了全民的阅读率。不过外国书籍价格 高昂也在迫使着高校图书馆社会化服务的发展, 国内 的书籍价格比较亲民化, 大多数民众都不会因为书籍 价格困扰, 导致无法阅读, 这也使得高校图书馆社会 化服务发展缺少动力。现在国内的图书馆社会化服务 仍然缺少一个完整的机制, 让高校面对社会公众, 并 且在当前新冠疫情依旧需要我们进行警惕的时候, 高 校需要考虑多方面情况对高校图书馆社会化服务做 出改善。

\section{3 高校图书馆社会化服务困境}

\section{1. 校园封闭管理}

当前许多高校为了保障校园安全依然采用着封 闭式管理, 限制校外人员进入, 要求进入校园的社会 人员要进行入校原因的登记, 对仅仅入校参观的人员 不予通行, 校园对于社会大众来说相对比较封闭。特 别是许多高校的图书馆通行是需要图书卡的, 只有教 师和学生能够进入图书馆借阅书籍, 高校图书馆对于 进出的管理更加严苛, 而这也成为了高校图书馆社会 化服务发展的一个难点。
在新冠疫情爆发后校园的出入管辖更加严苛, 对 入校人员的要求更高了, 这样的管理制度使得高校的 社会服务职能无法发挥作用。虽要发展高校图书馆社 会化服务, 但同时也要考虑疫情防控常态化的背景, 寻求创新路径, 在保证校园安全的状况下最大程度地 发挥校园的社会服务职责。

\section{2. 缺少相关规章制度}

目前的国家政策中缺少了对高校社会服务职责 的规定。政府没有意识到向大众开放是高校图书馆必 须要履行的一项义务, 对于高校图书馆社会化服务的 法律法规不够完善。部分地区的地方法规中有对高校 图书馆的法规，但其中的限制太多，也没有对具体的 执行方式有指导性意见。比如辽宁省针对高校图书馆 有着对外开放的法规, 但只要求中小学生入内, 对受 众群体范围十分狭小, 虽对高校图书馆社会化进程有 推进作用，但依旧不够完整。图书馆行业中，也缺少 能够促使高校图书馆社会化的具体操作章程, 让高校 在进行图书馆社会化服务时没有可以参照的方法论 也缺少相关的实践经验，也就难以进行科学的实践。 高校在缺少相关规章制度支持下，难以使得高校图书 馆社会化服务获得最大效益化。

\section{3. 传统思想束缚}

高校图书馆是我国文化软实力的象征, 高校领导 对于图书馆资源缺少共享理念, 在传统思维里, 高校 认为图书馆是校园的财产, 对于其公益性没有很好的 了解。高校图书馆长期的封闭性管理, 给学校带来了 这样的错觉。对于学生来说, 如果高校的图书馆对大 众开放, 那么图书馆内的人数会增加, 不利于自己的 学习和查阅资料, 处于这样的心理, 学生对高校图书 馆的开放也不抱有支持心态, 对高校图书馆的功能和 受众群体有着错误认知。并且对于社会大众来说, 由 于高校常年处于封闭状态，高校对于大众来说是像

“象牙塔”一般的存在，高校与社会大众的生活并不 贴近。并且大众对高校不允许校外人员入内的情况有 着固定思维, 认为高校图书馆只有校内学生才能够进 入, 这也就使得大众即使面对着知识短缺的难题, 也 不会想到走到高校图书馆中去解决问题。这些高校方 面与大众方面的认知错误也在一定程度之上不利于 高校图书馆社会化服务的推进。

\section{4. 高校经费问题}

许多高校的经费都存在短缺现象, 中国大多数公 办高等院校的建立本就出于公益目的, 盈利性并不高, 全然靠政府补贴支持的高等院校也不少见，高等院校 往往将资金投入在课程教学之中, 时常忽略图书馆建 设, 许多高校图书馆内都存在文献资料不足、书本破 旧、设备老化等等问题，这些问题致使高校图书馆在 部分情况下无法满足学生需求, 如果将高校图书馆社 会化, 就更加满足不了社会大众的需求。并且高校图 
书馆社会化服务向大众推出, 对图书馆内的人员也要 进行扩招, 这也对高校资金提出了要求。现在许多高 校都进行了扩招, 学生的增加也致使图书馆的阅读空 间变得狭隘，更加无法满足社会化服务的使用化、个 性化要求。

\section{5. 高校图书馆数字化水平不高}

随着互联网的发展, 现在几乎每一个人的生活中 都充斥着网络, 在网上阅读也成为了时兴的阅读方式。 现今国内高校几乎都已经设立了校园网, 也已经意识 到了学校建设中信息资源和应用软件的重要性, 但高 校依然没有将互联网的运用扩展到图书馆建设当中 许多高校的书籍信息资源不够, 数字化水平不高, 即 使在图书馆中有设立相关网络设备, 但也只是作为查 找书籍所在处的工具, 并没有将书籍内容信息录入网 络中。同时许多高校也没有在各类网络信息平台上运 营账号。许多高校图书馆场地有限, 也不发展图书馆 数字化建设, 致使图书馆内的文献无法增多, 使得无 论是学生还是公众, 在图书馆中获取的信息都是有限 的, 无法很好地满足读者阅读需求。

表 1：对几所大学微信平台发布内容的调查

\begin{tabular}{|c|c|c|}
\hline $\begin{array}{c}\text { 微信公众号 } \\
\text { 平台名称 }\end{array}$ & $\begin{array}{c}\text { 信息发布 } \\
\text { 量 }\end{array}$ & 信息内容 \\
\hline $\begin{array}{c}\text { 山东大学图 } \\
\text { 书馆 }\end{array}$ & 259 条 & $\begin{array}{c}\text { 荐书、读者分享 (专栏)、通 } \\
\text { 知、调查投票等 }\end{array}$ \\
\hline $\begin{array}{c}\text { 青岛农业大 } \\
\text { 学图书馆 }\end{array}$ & 224 条 & $\begin{array}{c}\text { 每日一句 (音频、专栏)、荐 } \\
\text { 书、征文发布、通知公告等 }\end{array}$ \\
\hline $\begin{array}{c}\text { 山东政法大 } \\
\text { 学图书馆 }\end{array}$ & 108 条 & $\begin{array}{l}\text { 校长荐书系列 (专栏)、好书 } \\
\text { 推荐、周末时光茂陵书香专 } \\
\text { 题 }\end{array}$ \\
\hline
\end{tabular}

\section{4. 高校图书馆社会化必要性}

\section{1. 公益性}

现在中国大多的高等院校都是公办院校, 高校的 建设和运作但靠学生的学费是无法支撑的, 其主要经 济来源是依靠政府的拨款和社会善款的赞助, 政府的 财政支持中大部分是源自税款, 中国社会主义税收体 制中的分配关系要求税款要取之于民用之于民, 这也 就对高校功能提出了要求, 高校建立的出发点便是为 了服务人民，这奠定了高校图书馆的公益性质。同时 我国的教育法也对高校的性质做出了规定, 高校是立 足于国家利益和社会利益之上的, 而不是以产生经济 利益为目的, 高校必须要承担起社会责任, 发展图书 馆社会化服务是高校发展的必经之路。

\section{2. 大众需求的增加}

当前社会在经历着社会需求的转型发展, 企业对 人才的要求越来越偏向于具有一定的专业知识和专
业技能，并进行创造性劳动并对社会作出贡献的人， 于是人们对各类信息资源的需求也随之而增长, 社会 大众对阅读书籍也愈加渴望, 对图书馆的依赖性也越 来越大。在这样的社会条件之下, 高校图书馆向社会 大众提供服务成为了社会发展的必然趋势。在此前的 网络调查之中，也有近四分之三的民众对高校图书馆 向大众开放表示了赞同, 并且认为高校师生是没有独 占图书馆书籍资源的权利的，图书馆的设立应该让社 会公众都能够受益。高校图书馆应该将向师生提供的 服务进一步扩展至社会大众, 给大众提供更加便捷的 信息获取方式, 为大众提供更大的智力支持和知识服 务, 这将成为高校图书馆的必然使命。

\section{3. 促进社会发展}

由于科技的不断发展, 信息和知识也在急剧增长, 社会对人们的素质要求变高了, 学习成为对每个人的 要求, 学习型社会的概念也应运而生。学习型社会是 美国学者罗伯特 - 哈钦斯在 1968 年提出的一个名词。 联合国科教文组织国际教育发展委员会编著, 被誉为 当代教育思想发展里程碑的著名报告《学会生存》中 强调终身教育和学习型社会两个概念, 将学习型社会 作为未来社会形态的构想和追求目标。我国在党的十 六大报告中提出, 将学习型社会作为全面建设小康社 会的一个重要目标。虽我国已经完成全面建设小康社 会目标, 但还是要坚持建设学习型社会, 让社会大众 形成终身阅读和终身学习的习惯。高校图书馆社会化 服务的建设, 能够给社会大众扩展阅读的渠道, 从一 定程度上促进全民阅读的建设, 加强社会主义精神文 明建设, 构建和谐社会。

\section{4. 图书馆自身发展需要}

随着互联网的蓬勃发展, 大众获取信息的渠道也 越来越多元化, 并且现在网络上的大多数信息都是免 费的，大众获取信息也是十分简单的，且仅通过一个 简单的移动终端, 大众就可以获取信息, 特别是对于 成长在互联网时代的新生代学生来说, 实体化书籍在 他们的生活中并不常见, 在日常生活中, 现在的学生 在查阅资料时更加偏向于使用手机或电脑。面对这样 的社会变化, 现在的图书馆行业受到了剧烈冲击, 迎 来了图书馆发展的危机，图书馆应该对此具备危机感， 及时根据现实情况调整服务机制和服务理念, 创新服 务方式，将服务的范围扩大。高校图书馆社会化服务 发展, 能够确立高校图书馆的社会地位, 全面的提高 图书馆的服务能力和竞争力。

\section{5. 推进高校图书馆社会化措施}

\section{1. 加快相关规章制度建设, 支持高校图书馆 社会化服务}

国家要加快相关法律法规建设, 加强国家的宏观 调控能力, 对高校图书馆社会化服务提出要求，督促 
高校采取行动。国家制定的法律法规要明确高校的社 会职能, 确定高校在社会中应付起的责任和义务, 保 证高校图书馆社会化服务的合法权益, 也要保障社会 大众在进入高校图书馆后的图书使用权，使高校图书 馆社会化服务在实际发展的路途中有法可依。同时政 府也要加大对高校建设的投入, 高校要平衡校园建设 中的资金投入, 加强对图书馆的建设，使图书馆能够 给学生提高知识水平的同时也能给大众带去服务。

\section{2. 加快高校图书馆数字化进程}

现在社会已经步入了信息时代, 网络充斥着我们 生活的方方面面, 信息的共享性也给高校图书馆发展 带去了机遇。在网络上分享信息成本不高, 传输效率 快, 能够提高信息资源的利用效率。想要将高校图书 馆中的信息资源充分利用起来, 就要将其信息化、数 字化。数字资源比起纸质资源更加便于管理, 存储空 间也变大了, 同时文献的查阅难度也大大降低, 在网 络文献资源中, 只要借助计算机软件便可以轻松对内 容进行检索。高校应该将图书馆中现有的信息资源上 传至网络, 增加可用资源, 打开学校文献资源的访问 渠道, 降低使用门槛, 这样能够方便学生随时对文献 资料进行查阅, 也能够方便大众进行阅读, 使用较低 的成本便能获得较高的社会效益。在新冠疫情局势依 旧严峻的现在, 图书馆信息资源的数字化也能大大降 低疾病传播概率, 保证校园和大众的安全。同时学校 也可以加强各类网络平台的运营, 比如让学生会或社 团在微博、微信公众号等平台创建账号, 在账号里发 布文献资源或阅读推荐, 利用这样的大众网络平台实 现高校的社会化服务, 同时也能增加高校的知名度, 一篇优秀的网络推文能够给大众带来深刻影响, 让大 众对学校培养人才的能力有清晰认识, 这种方式也能 够在实践中提升学生的能力, 培养优秀的全方位发展 人才。

\section{3. 更新对高校图书馆认知}

高校应该对高校的公益性有着清晰认识, 要明白 高校在社会中应当承担的社会责任, 才能在高校发展 中重视图书社会化服务。同时高校要利用已有资源, 通过多种渠道宣传高校图书馆社会化服务, 转变大众 的传统思维, 促使大众走进高校图书馆。高校可以通 过为社会大众举办培训活动来介绍高校图书馆社会 化服务, 帮助大众利用高校图书馆资源进行文献查阅, 让大众在对高校图书馆有使用意识的基础上提高大 众对文献资料的查阅能力, 通过这种活动能够提升大 众的学习意识, 提高高校图书馆的利用率, 提升社会 大众的文化素养。同时高校可以在网络上通过学校的 官方账号对图书馆进行宣传, 在抖音、微信公众号等 平台宣传本校的图书馆社会化服务, 吸引大众的目光。 这种方式在开展优质服务的同时，提高高校的知名度， 扩大高校的影响力, 以这样的方式争取到政府的重视 和支持, 吸引企业进行合作, 这对高校招生和学生就 业都有着好处。

\section{4. 提高图书馆管理能力, 增强图书馆工作人 员的服务意识}

高校图书馆在进行社会化服务建设时, 要完善图 书馆的管理机制, 高校图书馆对大众开放的一个重大 影响就是高校管理变得困难, 所以在图书馆建设中, 要制定面对图书馆管理员的各项评估和考核制度, 将 图书馆的管理成果作为工作最终考核的其中一项指 标, 提升图书馆领导面对社会化服务的积极性。高校 必须针对高校图书馆社会化服务建立有效管理的运 行机制, 让高校图书馆最大程度发挥其社会效益。高 校图书馆中的工作人员大多是由学生组成, 当今许多 高校图书馆中的工作人员只进行简单的借书还书操 作, 不能很好地为大众提供服务。高校要增强工作人 员的素质，让工作人员在工作中能够帮助图书馆中的 读者, 提升业务水平和工作能力, 增加其服务意识, 才能将高校图书馆社会化服务做到最好。

结论:

高校应该承担起社会责任，推进高校图书馆社会 化服务建设，最大程度地满足社会大众对于获取信息 的需求, 高校应该结合现实实际情况清楚认识到高校 图书馆建设的缺陷, 最大程度的利用现有资源对高校 图书馆进行创新改革, 推进图书馆数字化建设, 将图 书馆面向大众开放, 为构建社会主义和谐社会贡献一 份力量。

\section{REFERENCES}

[1] Li Juwei. Dilemma and countermeasures of university library service under epidemic prevention and control [J]. Modern Rural Science and Technology, 2021(07):95-96.

[2] Zhang Yanyan, Yu Bo, Guo Lei, Wen Liangming. Research on Service Innovation of University Library in Fragmented Reading Era [J]. Library Construction, 2017(04):44-50.

[3] Zhao Xueyan, Peng Yan. Research on the advantages and paths of university libraries participating in the construction and service of university think tanks [J]. Library and Information Work, 2016,60(22):28-33.

[4] Zhou Xiaoyan, Zai Bingxin. Looking at the development trend of foreign university libraries from strategic planning — Taking the strategic planning of 28 world-class university libraries as an example [J]. journal of academic libraries, 2016,34(01):62-68.

[5] Cheng Huanwen, Huang Mengqi. Between "paper worship" and "digital support"-the dilemma and 
outlet of information resources construction in university libraries [J]. Library Forum, 2015,35(04):1-8.

[6] Yuan Jun. analysis of technical support services of university libraries in post-epidemic era-taking the investigation of technical support services of 18 university libraries in Tianjin as an example [J]. library work and research, 2021(07):41-48. 